Primary Publication: Colloid and Polymer Science (2014) 292: 2983-2992, DOI 10.1007/s00396-014-3347-0

\title{
How Much Weighs the Swelling Pressure
}

\author{
Patrick Höhne, Klaus Tauer \\ Max Planck Institute of Colloids and Interfaces \\ D-14424 Potsdam, Germany
}

\begin{abstract}
We are presenting a new method to study the swelling of gels by following the apparent weight increase during confined swelling. This method, compared to other procedures, is characterized by its simplicity and versatility to study the influence of the experimental conditions such as composition of the swelling agent and temperature. Examples are given for poly(acrylic acid) and poly( $\mathrm{N}$-isopropyl acrylamide) hydrogels and the influence of ethanol content, $\mathrm{pH}$, and temperature in the water pool.
\end{abstract}

Keywords: swelling pressure, hydrogels, solvent composition, temperature influence 


\section{Introduction}

Swelling can be defined in a general way as the imbibition of a fluid by a body leading to changes of shape and volume (mainly increase). This definition distinguishes swelling from pure capillary suction which does not cause volume changes. Swelling (as well as deswelling) is ubiquitous in all kinds of dead and living soft matter. In nature, water is abundant and water or an aqueous solution is the exclusive swelling agent. Swelling in nature is not restricted to solely living organisms. For instance, the interaction with water activates plant seeds via swelling and contributes to propagation of many species [1-3]. It is important to emphasize that the uptake of water provides a very specific energy source independent of sun light and chemical reactions. Swelling makes a rigid material soft and flexible. It exerts stress and can create mechanical work.

Biological materials (algae, seeds, plant tissues, gelatine, and natural rubber) were starting points for early swelling studies [1,3-6]. Nowadays, swelling is one of the basic scientific pillars in biology, polymer and colloid science where corresponding studies contribute a great deal to our understanding in these areas.

Swelling pressure studies have quite a long history [3,5,7-11]. This is by far not a complete list of references but only a few marking essential steps in this development. These are examples of measuring the swelling pressure directly by pressure gauges (manometers) or by means of ultracentrifugation. The latter method has the advantage that composition dependence of the swelling pressure is obtained in just a single experiment [9]. Progressing miniaturization of devices for pressure measurements stimulated during the last decade the development of small sensors utilizing the swelling pressure of gels [12-17].

In biology and medicine the swelling pressure plays a major role in the function of connective tissues and hence, methods have been developed to study for example the isometric compressive stress of cartilage in a sophisticated apparatus with feedback control to ensure strict volume constancy [18].

In this study we report the exploration of a different method regarding the characterization of gel swelling under confined conditions which is experimentally simple and easily allows carrying out modifications during the swelling process. The practical examples in this study are exclusively hydrogels, but the method is not restricted to aqueous systems. 


\section{Experimental information}

\section{Materials}

NIPAM (Acros Organics) has been recrystallized in an hexane:toluol mixture (ratio 5:1). Acrylic acid (Acros Organics) has been freed from the stabilizer by distillation under reduced pressure. Ammonium peroxodisulfate (APS, Aldrich), and N,N'-methylene bisacrylamide (MBA, Fluka), Pluronic F-108 (Aldrich), sodium hydroxide (Fluka), sodium bicarbonate (Acros Organics) and poly(styrene sulfonate sodium salt (PSS, Aldrich) were used as received. Water was taken from a SG purification system (Hamburg) with a conductivity of $0.055 \mu \mathrm{S} \mathrm{cm}^{-1}$.

\section{Gel Syntheses}

The polyacrylic acid gels were prepared in a glass tube with an inner diameter of $10 \mathrm{~mm}$ to achieve a dried polymer monolith with an outer diameter of approximately $7 \mathrm{~mm}$. For the precursor solution $1.05 \mathrm{~g}$ of distilled acrylic acid has been added to $2 \mathrm{~g}$ of water. Further the crosllinker $\mathrm{N}, \mathrm{N}$ '-methylene bisacrylamide (1.4 wt\%), N,N,N',N'-tetramethyl ethylene diamine as accelerator (3.0 wt\%), Pluronic F108 as surfactant ( $4.8 \mathrm{wt} \%$ ) and $700 \mu \mathrm{L}$ sodium hydroxide solution $(22 \mathrm{~mol} / \mathrm{L})$ for $\mathrm{pH}$ adjustment were added and the solution was stirred for 20 minutes. After adding ammonium peroxydisulfate (1 wt\%) the bulk gel was left at room temperature for polymerization over night while for the porous gel 200 $\mathrm{mg}$ of sodium bicarbonate where added two minutes after the initiator and very slightly mixed with a spatula. The porous gel could be taken out of the reaction vial after a couple of minutes.

For synthesis of the PNIPAM-PSS interpenetrating polymer network gel 3,0 g of NIPAM were dissolved in $30 \mathrm{~mL}$ of water. Then $10 \mathrm{wt} \%$ referring to the NIPAM monomer mass of poly(sodium styrensulfonate) (molecular weight $70 \mathrm{kD}$ ), 1,3 wt\% of the crosslinker $\mathrm{N}, \mathrm{N}^{\prime}$-methylenebisacrylamide and $1 \mathrm{wt} \%$ of the accelerator $\mathrm{N}, \mathrm{N}, \mathrm{N}^{\prime}, \mathrm{N}^{\prime}$-tetramethylethylenediamine were added and the solution degassed for 30 minutes and stirred for further 20 minutes. Finally $39 \mathrm{mg}$ APS in $400 \mu \mathrm{L}$ were added and the solution was kept under argon atmosphere for polymerization for the following ten hours.

\section{Methods}

As balance a Sartorius Practum 5101-1S with an USB interface for direct data transfer to excel was used. That balances uses the so called DMS measurement principle, where an electrical wire is expanded upon loading and the difference in the electrical resistance is used to measure the load the scale pan is exposed to. Therefor this system depends on a slight lowering of the scale pan. The scale readout is monitored and the apparent mass is corrected by contributing the amount of evaporating water which was determined in kind of calibration experiments in the absence of the gel under otherwise identical conditions.

In our setup heating of the water pool was achieved by dipping in a platinum wire connected to an electric DC source (2.3-2.4 V, 16.5 A, so-called resistive heating) and cooling simply by allowing the temperature to return to ambient conditions after turning off the electrical heating. Heating and cooling rate was 145 and $127 \mathrm{mK} / \mathrm{min}$, respectively.

Temperature measurements were done with a Voltcraft K204 4-channel digital thermometer and datalogger with RS232 interface and 4 K-type sensors for temperatures up to $200{ }^{\circ} \mathrm{C}$. Smoothing of the noisy data has been carried out with the 2D smoothing algorithm of SigmaPlot (version 12.5).

The change in the speed of sound was measured with the ResoScan URT System (TF Instruments $\mathrm{GmbH}$, Heidelberg, Germany) based on ultrasound resonator technology with heating and cooling rate of $300 \mathrm{mK} / \mathrm{min}$. The method can also be used for swollen gels, provided the gel content is low enough (about $0.8 \mathrm{mg}$ of dry PNIPAM-PSS gel per $200 \mathrm{mg}$ of water worked fine). 


\section{Results and Discussion}

In order to use the mechanical work (which is the product of volume and pressure), swelling must be confined. The confinement of swelling matter produces a swelling pressure, $\Delta \mathrm{P}_{\text {swell }}$, which in analogy to the osmotic pressure contributes to the equilibration of the chemical potential of the swelling agent outside and inside the swollen gel, $\mu_{10}$ and $\mu_{1 s g}$, respectively (equation (1)). Here $v_{m, s a}$ is the molar volume of the swelling agent in the gel. In general, flexible walls at specific sides of the confinement allow to focus the force in certain directions and to trigger selective actions. In this sense, gels are used as actuators where external stimuli are applied that control imbibition and expel of the swelling agent [19].

$$
\Delta \mathrm{P}_{\text {swel }}=\frac{1}{\mathrm{v}_{\mathrm{m}, \mathrm{sa}}}\left(\mu_{10}-\mu_{1 \mathrm{sg}}\right)=\frac{1}{\mathrm{v}_{\mathrm{m}, \mathrm{sa}}} \Delta \mu_{1}=\frac{\Delta \mathrm{w}_{\mathrm{sg}}}{\mathrm{a}_{\mathrm{g}}}=\frac{\Delta \mathrm{m}_{\mathrm{sg}} \cdot \mathrm{g}}{\mathrm{a}_{\mathrm{g}}}
$$

\section{Constructive Aspects}

Considering equation (1), the swelling pressure is related to the weight force of the swelling gel $\left(\Delta \mathrm{w}_{\mathrm{sg}}\right)$ applied to a given area $\left(\mathrm{a}_{\mathrm{g}}\right)$ which is accessible by weighing, that is, by following an apparent mass change during the gel swelling, $\Delta \mathrm{m}_{\mathrm{sg}}$. That mass change can be monitored easily by a scale if a proper setup is used (cf. Figure 1). Because the scale readout corresponds to an apparent mass change, we call this procedure the apparent mass method (AMM). It should be noted that the values of the displayed apparent masses depend on the contact area between the gel and the PTFE stamp ( $t$ in Fig. 1 a). This is a fundamental difference to weighing of real masses.

a)

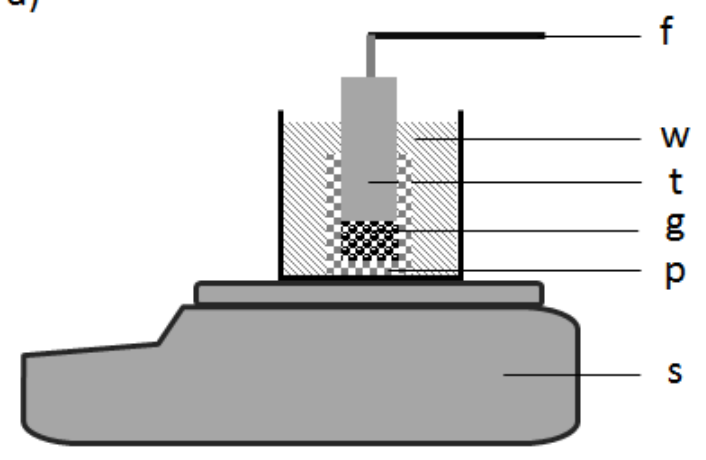

b)

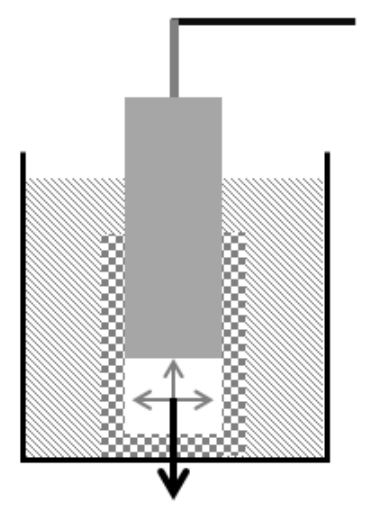

Figure 1. a) Schematic drawing of the setup used to monitor the swelling of spatially confined gels using a scale with $\mathrm{s}$ - scale connected with computer to automatically monitor data, $\mathrm{p}$-porous glass filter tube (pore size G1, pore size $100-160 \mu \mathrm{m}$ ) fitting to the PTFE stamp,; $\mathrm{g}$ - gel, $\mathrm{t}$ - PTFE stamp, $\mathrm{w}$ - water reservoir, $f$ - clamp bolted to a fixed support stand

b) Schematic illustration of the forces inside the swelling gel, the black arrows indicates the redirection of the forces acting on the scale

The most important feature of the experimental method to study confined gel swelling as sketched in Figure 1 (cf. also Figure S-1 and S-2 in the supporting information) is the construction of the confinement particularly how tightly the gel fits to the confinement and the easiness to establish contact with the swelling agent. How tightly the gel fits in the cell is important because the more water can additionally get in, the lower the polymer volume fraction and according to equation (1) 
also the apparent mass. Another important aspect of the setup is the easy accessibility of the swelling agent (water pool) allowing simple measurements (temperature, conductivity, $\mathrm{pH}$, etc.) and manipulations (addition of matter or application of electromagnetic fields). This feature, allowing readily the application of external stimuli on the system and the monitoring of more than just one property simultaneously during swelling studies, is of special importance. Particularly, this possibility is useful for studying the influence of external temperature effects, changing solvent quality, and an electric or magnetic field on the confined swelling of charged gels and magnetic gels, respectively.

In addition, the consideration of the mass change associated with swelling of gels in confined space allows quite an impressive illustration of the magnitude of force acting during this process. According to equation (1), a swelling pressure of one MPa should be able to generate at an area of one $\mathrm{cm}^{2}$ (here on earth) a scale readout of $10.2 \mathrm{~kg}$, provided the forces are completely redirected towards the scale. Practical examples are quite instructive and reveal the peculiarities of this procedure. It seems practically impossible that the swelling pressure can be completely redirected towards the scale because there will always be certain losses in the PTFE stamp and the material of the rack construction due to the elasticity and springy properties of the materials and of the connection points. This fact clearly limits the application of AMM with respect to quantitative determinations of thermodynamic properties of the gel. Despite this drawback, comparison studies characterizing the temporal development of swelling, the behavior of different gels, or the influence of different conditions in the water pool are readily possible.

It is also important to recall that according to (1) the swelling pressure increases with decreasing volume fraction of swelling agent in the gel $[20,21]$. Thus, the equilibrium between pure gel and pure swelling agent would generate an infinite high swelling pressure. But this is purely hypothetical and cannot be realized experimentally because the occurrence of a chemical potential requires contact between both phases which immediately causes minimum swelling of the gel and dropping of the swelling pressure below infinity.

The data put together in Figure $\mathbf{2}$ show the development of the scale reading (the apparent mass) with time for a porous PAA-gel and reveal the enormous influence of the structural design of the confined space embedding the gel on the scale readout. In general for a given geometry of the contact area with water in the gel compartment, the tighter the gel fits into the confinement (the closer the contact to the walls) the greater the displayed value of the mass (cf. case 2 and 3 of Figure 2). In a series of tests it was figured out that, in order to establish the contact with water, porous walls of the gel compartment (case 4 of Figure 2) are more advantageous compared to the direct contact (case 2 and 3 of Figure 2). If, however, the porous part of the confinement is too low, the scale readout is also low (case 1 of Figure 2). This behavior can be explained with gel blocking $[16,17,22]$ which describes the reduction of water inflow with increasing swelling of the gel layer in direct contact with water due to the confined geometry. 

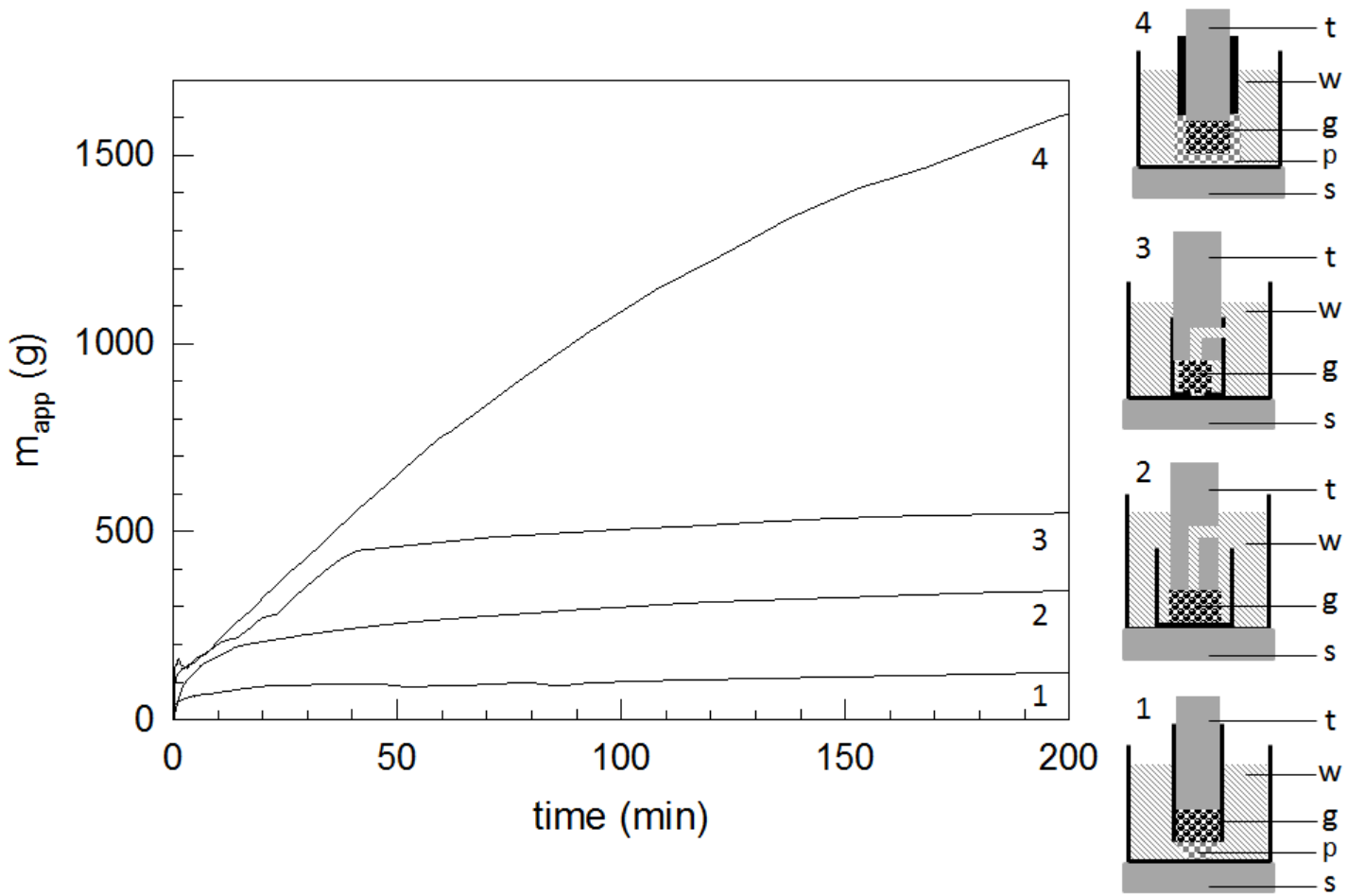

Figure 2. Correlation between the scale readout (defined as apparent mass, $m_{a p p}$ ) and contact time with water for PAA gels in different realizations of the confinement. The sketches on the right hand side illustrate four different confinements with varying geometry and contact to the swelling agent (water). The numbers $1-4$ correlate the various experimental setups to the $m_{a p p}-$ time curves.

Of all the investigated confinements, case 4 leads to the highest increase of the apparent mass (highest swelling pressure) due to the lowest $\mu_{1 \mathrm{sg}}$ (cf. equation (1) or the highest polymer volume fraction in the confinement. In this setup the dimensions of the confining porous glass cell containing the gel are as follows (cf. supporting information): height 6.5, diameter 7.4, and wall thickness 2.4 $\mathrm{mm}$.

\section{The Morphology of the Gel}

In addition to the constructive aspects of the confinement, the nature and the consistence of the gel plays a crucial role as illustrated by the examples given in Figure 3. In the first case, $39.6 \mathrm{mg}$ of a quite soft porous PAA-gel confined in a cylindrical cell (diameter: $8.12 \mathrm{~mm}$ and height: $6.36 \mathrm{~mm}$ ) generates apparently in swelling equilibrium a mass of about $1.5 \mathrm{~kg}$ (cf. Figure 2). $165 \mathrm{mg}$ of a nonporous, solid PAA-gel causes an apparent mass of about $3 \mathrm{~kg}$. Clearly, these readings of the scale do not mean that the corresponding quantity of water has been imbibed by the gel. This is physically impossible since the height of the confining cylinder increases during swelling, caused by the construction of the balance, only by $1.24 \cdot 10^{-4} \mathrm{~mm} / \mathrm{g}$ due to motion of the scale table. The motion of the scale table under load causes for the two gels shown in Figure 3 an increase in the height of the confining cylinder at most of 186 and $372 \mu \mathrm{m}$, respectively. The apparent mass ratio of 38,000 and 18,000 ( $\mathrm{g}$ of water to $\mathrm{g}$ of gel) in the first and second case, respectively, is rather an expression how eager the gel is to water and how easy it is for the gel to imbibe water. In other words, the scale reading is an illustrative manifestation (in fact it is the visualization) of the chemical potential difference $\Delta \mu_{1}$ (cf. equation (1)) or of 'the desire of the gel to water'. The fact that the apparent mass for the solid gel increases faster and reaches a higher value compared with porous gel is reasonable. 
In the latter case the polymer volume fraction in the confinement is lower and during the swelling process the compression of the pores absorbs a certain portion of the force. Again, following the above discussion regarding the meaning of the swelling pressure, increasing $\mathrm{m}_{\mathrm{app}}$ does not mean an increasing uptake of water by the gel with time as it might be suggested by the experimental data. If this would happen, the result should be a decrease in the swelling pressure and $m_{a p p}$, cf. (1). The increase of $m_{a p p}$ with time is rather an expression of the development of the desire of the gel to swelling agent which is another description for the chemical potential.

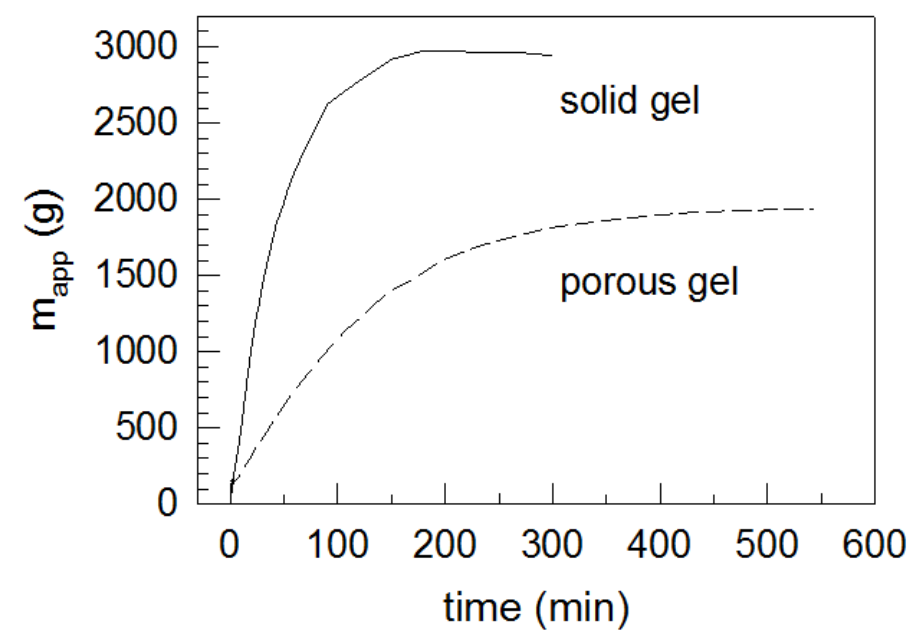

Figure 3. Dynamics of confined swelling of porous and solid PAA gel in an experimental setup corresponding to case 4 as shown in Figure 1

The observation of swelling in confined geometry with a scale in an arrangement as shown in Figure 1 allows also to follow the swelling dynamics and to track the influence of changes in the swelling conditions inside and outside the gel of which a few cases will be discussed in detail below.

The influence of Solvent Quality

The first case illustrates how an alteration of the solvency of the swelling agent, realized by stepwise addition of ethanol, influences the confined swelling of a PAA gel. Ethanol is a nonsolvent for PAA and hence, upon ethanol addition the swelling should be reduced corresponding to decreasing apparent mass as it is indeed observed and displayed in Figure 4. 


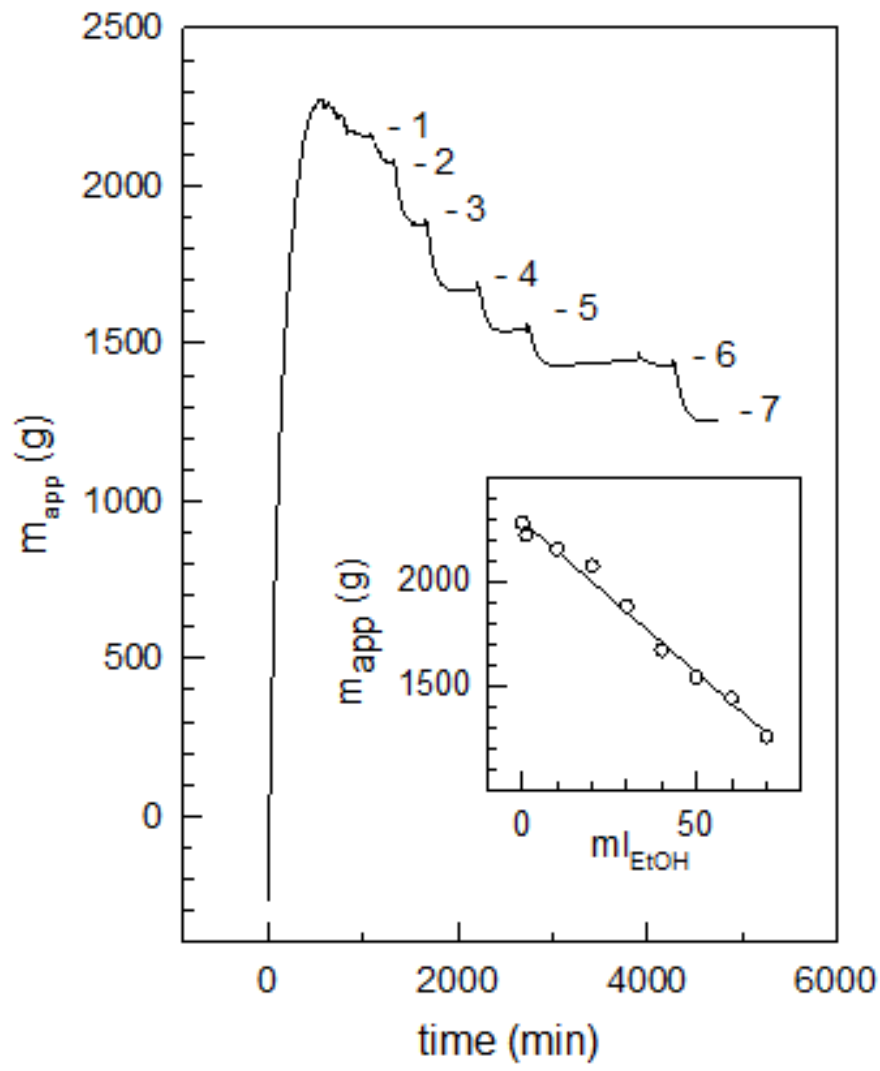

Figure 4. The change of the apparent mass $\left(m_{a p p}\right)$ of a PAA gel swelling with water with increasing concentration of ethanol in the swelling agent; the numbers $(1-7)$ indicate the levels of $m_{\text {app }}$ after repeated addition of $10 \mathrm{ml}$ of ethanol; the inset graph shows the plateau value of $\mathrm{m}_{\text {app }}$ reached after each addition in dependence of the cumulative volume of ethanol $\left(\mathrm{ml}_{\mathrm{EtOH}}\right)$

The solvency of water for PAA can also be modified by changing the $\mathrm{pH}$ and / or increasing the ionic strength as shown by the data depicted in Figure 5. Alternating the $\mathrm{pH}$ between basic and acidic by addition of sodium hydroxide and sulfuric acid, respectively, leads also to an increase in the ionic strength. The experimental data show an influence of both, the $\mathrm{pH}$ and the ionic strength. 


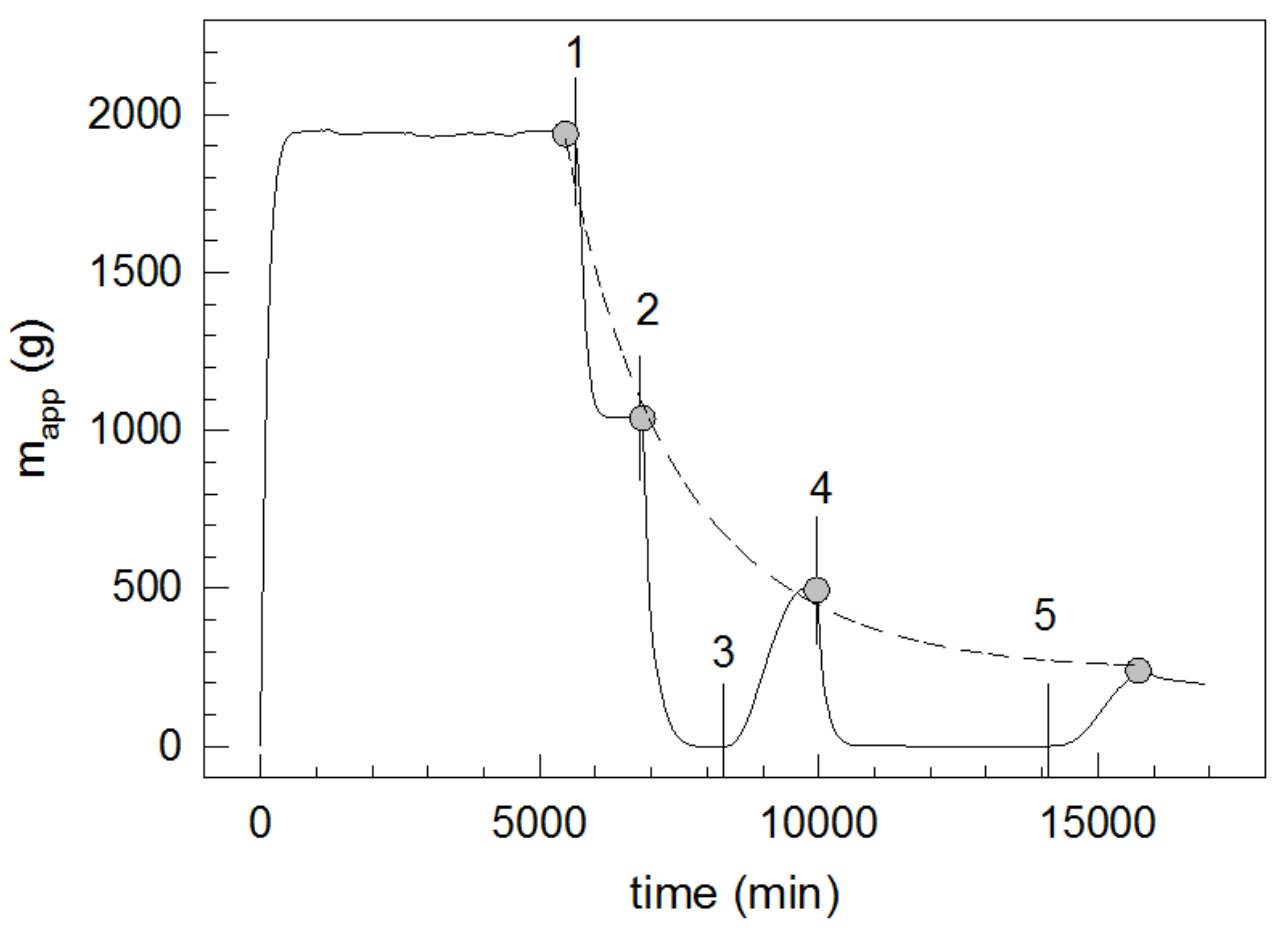

Figure 5. The change of the apparent mass $\left(m_{\text {app }}\right)$ of a PAA gel in pure water (from time 0 to point 1 ) and after alternating addition of sodium hydroxide $(0.88 \mathrm{~g}$ of $\mathrm{NaOH} / \mathrm{ml}$ of water) and sulfuric acid; at the time marks by $1-\mathrm{NaOH}, 2-\mathrm{H}_{2} \mathrm{SO}_{4}, 3-\mathrm{NaOH}, 4-\mathrm{H}_{2} \mathrm{SO}_{4}, 5-\mathrm{NaOH}$ was added; the amounts of base and acid added were adjusted to achieve after each base and acid addition a pH of about 13 and 1 , respectively; the dashed line is a fit of the grey points and describes the response of the swollen gel under basic conditions on the ionic strength which increases from point 1 (pure water) to point 5 up to a value of about $5.5 \mathrm{M}$

\section{Temperature of the Water Pool}

The second case deals with the influence of external temperature changes on swelling (Figure 6). The evaluation of results caused by any change in temperature requires the consideration of the thermal expansion of the materials involved. For the experimental setup used (cf. Figure 1 and supporting information) the crucial contribution comes from PTFE because its linear thermal expansivity is at 20 ${ }^{\circ} \mathrm{C}$ by more than a factor of 30 higher than that of borosilicate glass [23]. The quite strong thermal expansivity of the PTFE stamp (label $t$ in Figure 1a) generates a force which vertical downward component adds directly to the scale readout. In addition, the vertical upward component acts on the connecting rack (label $f$ in Figure 1a) where a part of the force is absorbed by the elasticity of both the construction and the material. The stiffer the connection is, the higher the fraction of the force contributing to the scale readout. This deliberation means that the influence of the temperature of the scale readout depends on the degree of swelling of the sample under consideration. Accordingly, a higher swelling pressure can cause a higher tension or stiffness in the connecting rack which in turn should redirect a higher portion of the force to the scale. The validity of these considerations is proven by the experimental results displayed in Figure 6 . The experimental data show that both the temperature and the scale readout react simultaneously regardless of whether a gel is present or not. 

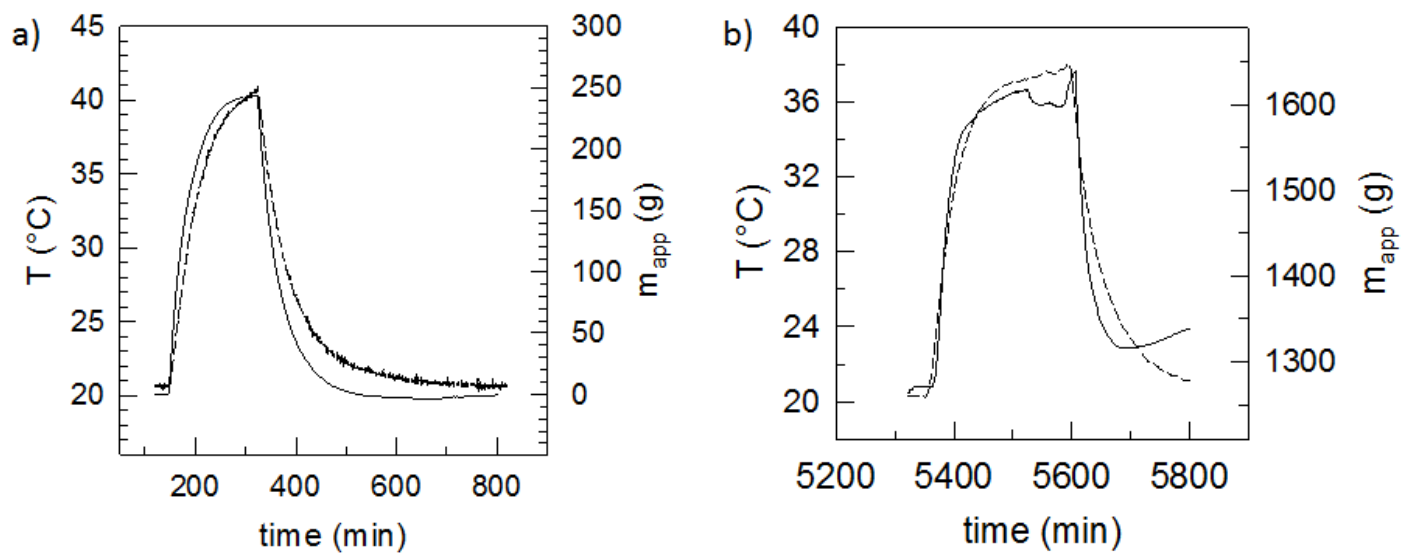

Figure 6. Correlation between the change of the temperature ( $T$ dashed lines) and the scale readout ( $m_{\text {app }}$ solid lines) for a gel-free comparison run without any preload (graph a)) and a porous PAA gel in the swollen state (graph b)); the heating rate was $0,145 \mathrm{~K} / \mathrm{min}$ and the cooling rate $0,127 \mathrm{~K} / \mathrm{min}$

The data of Figure 6 apparently suggest that the influence of temperature on the apparent mass is higher if the setup is filled with a gel. However, these data do not allow this conclusion because neither the difference in the final temperature nor in the preload before increasing the temperature between both runs has been taken into account. The consideration of these important experimental conditions is done by means of the ratio $\left(m_{\max }-m_{0}\right) /\left(T_{\max }-T_{0}\right)$ where the numerator and denominator is the difference in the apparent mass and the temperature, respectively, with the index ' 0 ' describes the initial conditions (before heating) and ' $\mathrm{max}^{\prime}$ at maximum or given temperature (cf. Figure 7).

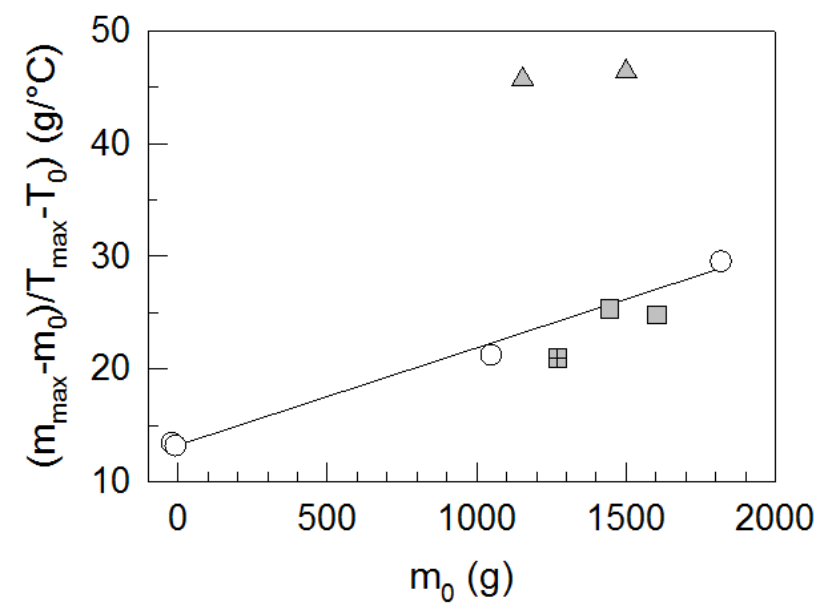

Figure 7. Correlation between the ratio $\left(m_{\max }-m_{0}\right) /\left(T_{\max }-T_{0}\right)$ illustrating the influence of increasing temperature on the scale readout and the preload $\left(m_{0}\right)$ which is the scale readout before heating; the white circles are data for the gel-free setup with a regression line, the grey crossed and the grey square is for a porous and bulky PAA gel, respectively, and the grey triangles are for a PNIPAM-PSS gel

The data of Figure 7 prove the conclusion of the discussion above regarding the influence of the preload on the temperature effect caused by thermal expansion of the PTFE stamp. In addition, this result shows that the scale readout represents only the portion of the swelling pressure that is redirected effectively towards the scale. 
The upper triangles in Figure 7 represent the behavior of bulky PNIPAM-PSS gels. For this kind of gel we considered a temperature range of only a few degrees, about 5 degrees in comparison to about 20 degrees for the other cases, to stay far enough away from the lower critical solution temperature (LCST) of about $32{ }^{\circ} \mathrm{C}$. Interestingly, the results show quite a huge difference between both gel types. In contrast to the PNIPAM-PSS gel, there is almost no extra, gel material-induced temperature influence on the swelling of the porous PAA gel detectable. For the former gel an extra temperature contribution, even below the LCST, is clearly to be seen.

An interesting question is what happens with the PNIPAM-PSS gel when the temperature change sweeps over the range of the LCST? Figure 8 shows the answer and reveals that in this case, the synchronism of the temperature and the mass curve, as it is observed for the empty setup and the PAA gel (cf. Figure 6), is broken.

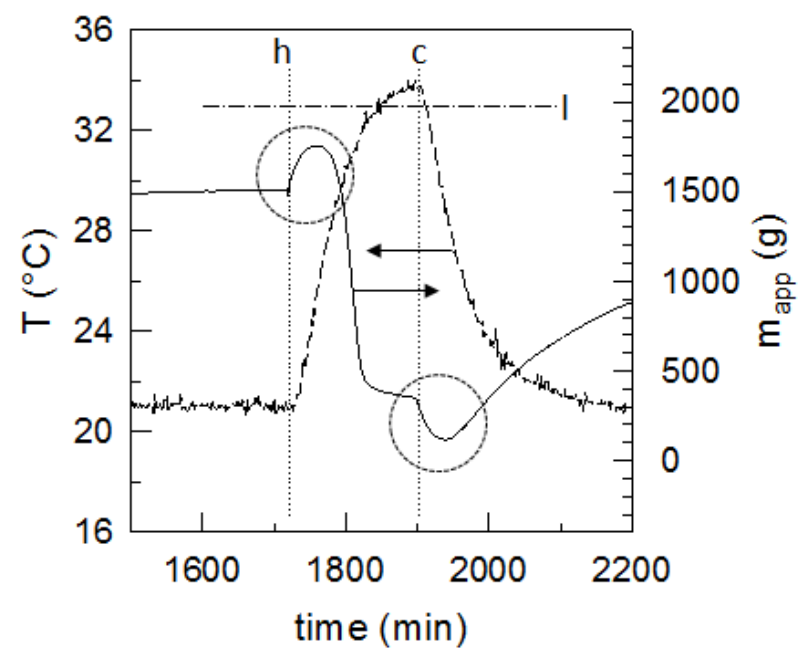

Figure 8. Correlation between the change of the temperature ( $T$ dashed line) and the scale readout ( $m_{\text {app }}$ solid line) for a PNIPAM-PSS gel; the vertical dotted lines labeled ' $h$ ' and ' $c$ ' mark the switch on and off of electric heating, respectively, the dashed-dotted horizontal line ' $\mathrm{l}$ ' marks the LCST of the gel, the dotted circles mark maximum and minimum in the $\mathrm{m}_{\mathrm{app}}$ - time curve; the heating rate was $0,145 \mathrm{~K} / \mathrm{min}$ and the cooling rate $0,127 \mathrm{~K} / \mathrm{min}$

The temperature-dependent scale readout for thermoresponsive samples is the results of a superposition of the thermal properties of the setup and the gel. When, as here in the case of a gel with a LCST, the changes of thermal properties of the gel and the material of the setup in dependence on temperature are opposite (the gel contracts and the PTFE expands with temperature increase and vice versa), the resulting curve possesses maxima and / or minima. The data of Figure 8 show such behavior for the PNIPAM-PSS gel. Immediately after heating the thermal expansion of the PTFE is the dominating effect and overrules the increasing shrinkage of the PNIPAM gel. After the maximum in the $\mathrm{m}_{\mathrm{app}}$ curve at a temperature of $25.4{ }^{\circ} \mathrm{C}$ the deswelling of the PNIPAM governs the scene. This happens about 8 degrees below the LCST which is quite an astonishing result because so far, only moderate changes in the PNIPAM solution state have been described in this temperature range [24-30]. Moreover, $25^{\circ} \mathrm{C}$ is frequently used as starting or reference temperature for deswelling studies [26,29-33]. Long-time changes in the interaction between PNIPAM and water after passing the LCST towards higher temperatures have been known already for a few years [32]. Also upon cooling the initial behavior is dominated by the thermal property (this time shrinking) of the PTFE 
and only below a temperature of $28.7^{\circ} \mathrm{C}$, after the minimum in the $\mathrm{m}_{\text {app }}$ - time curve, the swelling of the PNIPAM dominates the further changes in the apparent mass.

Another interesting question is whether the method is suited to characterize the LCST behavior of PNIPAM-PSS gel and if yes, how to compare the data with other methods such as ultrasound resonator technology (URT). URT evaluates the temperature dependence of the difference in the speed of sound $(\Delta U)$ between a solution and pure water and belongs to the methods with an extremely high resolution in measurements of physical parameters of solutions and colloidal suspensions [34]. Recently this technique has also been successfully applied to study the thermoreversible properties of PNIPAM [35] and PNIPAM-b-PSS block copolymers solutions [32,33].The speed of sounds $(U)$ depends in fluids on the compressibility and density of the medium. With increasing temperature PNIPAM becomes more hydrophobic and water molecules are released and the speed of sound decreases compared with pure water in the reference cell. With URT we are tracking quantitatively changes in the adhering layer of water molecules and hence, this method allows convenient characterization of thermoresponsive samples.

For the data evaluation the heating and cooling cycles of the gel have been considered separately and the temperature derivative of $m_{a p p}$ and the speed of sound have been used to determine the critical temperature. The results are summarized in Figure $\mathbf{9}$ and reveal quite an interesting finding since the AMM method shows no LCST upon cooling.
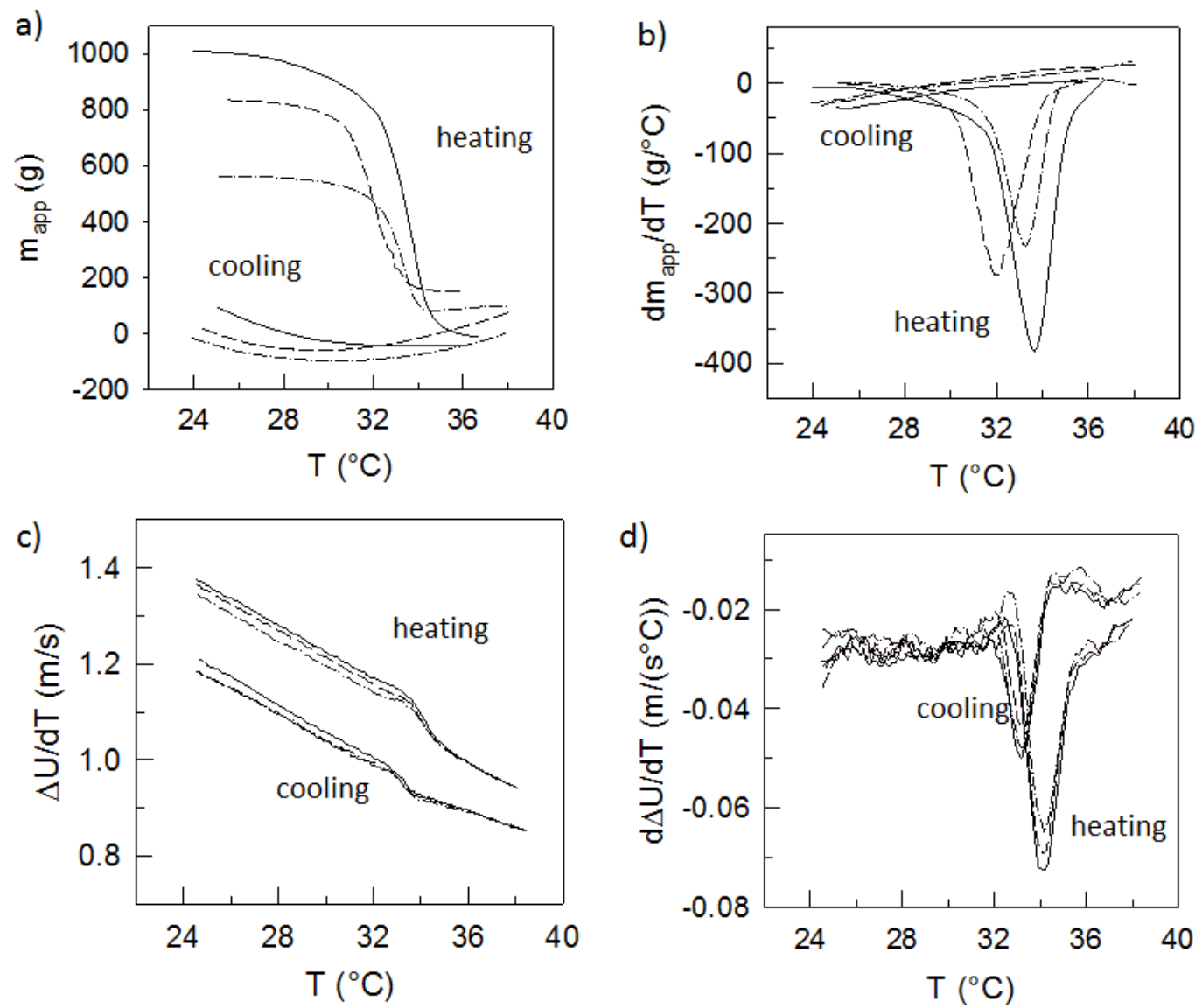

Figure 9. Evaluation of heating and cooling cycles of the PNIPAM-PSS gel by means of AMM [graph a) and b)] and URT [graph c) and d)]; graph a) and c) show the correlation between the temperature and $\mathrm{m}_{\mathrm{app}}$ and $\Delta \mathrm{U}$, respectively; graph $\mathrm{c}$ ) and d) display the correlation between and the temperature 
derivative of $m_{\text {app }}$ and $\Delta U$, respectively; the heating rate was $0,145 \mathrm{~K} / \mathrm{min}$ and the cooling rate 0,127 $\mathrm{K} / \mathrm{min}$ for $\mathrm{AMM}$ and $0.3 \mathrm{~K} / \mathrm{min}$ for URT

The lack of a LCST upon cooling in the study of the thermoresponsive properties with the AMM is a direct consequence of the fact that the scale readout is immediately after deploying the change of temperature dominated by the shrinking of the PTFE stamp. This dominance overruling the effect of the PNIPAM - water interaction lasts until the water has cooled down to $28.7^{\circ} \mathrm{C}$.

The AMM shows a higher experimental scatter than the URT in studying the thermoresponsive properties of the PNIPAM-PSS gel. The average LCST value upon heating as determined by URT and AMM is $34.1 \pm 0.2$ and $33.0 \pm 0.9{ }^{\circ} \mathrm{C}$, respectively. The critical temperature extracted from the URT cooling cycles is slightly lower $\left(33.2 \pm 0.2^{\circ} \mathrm{C}\right)$ and confirms the known heating - cooling hysteresis for PNIPAM [32]. The difference of the LCST as determined with AMM and URT can have two possible causes. The first is due to the superposition of two opposing effects in the AMM as discussed above, and the second is due to the fact that URT measures the free but AMM the confined swelling deswelling cycle of the gel.

\section{Heat Effect of Swelling}

The last example describes attempts to follow the temperature changes during isochoric swelling. In principle, the experimental easiness to measure temperatures during the AMM offers the possibility to get an idea regarding heat effects associated with confined swelling. We are absolutely clear about the difficulties in trying to carry out a kind of caloric investigation with an open apparatus in an open laboratory environment like the experimental arrangement used in this study. In order to check whether some reasonable conclusions can be drawn under these conditions, temperatures have been measured at different spots of the experimental setup (cf. also Figure S-1). The first temperature sensor has been placed inside the gel (label ' $g$ ' in Figure 1a)), the second inside the water pool (label ' $w$ ' in Figure 1a)), the third inside a reference water pool which was placed near the beaker containing the gel, and the fourth sensor monitored the air temperature in the laboratory hood. Tracking of temporal changes in these temperatures after the contact between the gel and the water has been established should allow getting some clues about possible heat effects.

The data put together in Figure $\mathbf{1 0}$ seem to support this idea. During the initial thermal equilibration period the contact between the water and the gel was blocked by an impermeable membrane surrounding the gel compartment. In the graphs time zero corresponds to the removal of the membrane. The monitoring of the temperature has been continued until $m_{a p p}$ has reached a constant value of about $1783 \mathrm{~g}$ (data not shown here). The curves displayed are smoothed data sets (cf. experimental information). Graph a) of Figure $\mathbf{1 0}$ shows the time course of temperature of the four spots and allows two important conclusions. Firstly, the results are reasonable because all temperature profiles show the same general trend. The temperature of the reference water pool (curve 3 ) is in the time period up to about 1100 minutes half a degree lower than the temperatures measured at the other three spots. This is caused by an enhanced evaporation and the direct effect of the evaporation cooling. After covering the beaker, the temperature increases and reaches the range of the other sensors. This result proves the sensitivity of the temperature measurements and strengthens our confidence in the results. Secondly, the gap between the temperatures of sensor 1 and 4 or 2 and 4 widens with increasing time (corresponding to increasing $m_{a p p}$ ) which points towards a measureable heat effect during isochoric swelling. The next straightforward step in the data evaluation is the consideration of temperature differences. This procedure seems to be justified by the equality of the four temperature trends as expression of the overall temperature change in the environment of the experimental setup. Graph b) of Figure $\mathbf{1 0}$ displays four temperature 
differences, in the time range until the $m_{\text {app }}$ increases from zero to about $1750 \mathrm{~g}$, which allow conclusions regarding the heat effect. Difference $\Delta 1$ is that between the water pool (T2) and the water in the reference beaker (T3), $\Delta 2$ between the gel (T1) and T3, $\Delta 3$ between the air temperature (T4) and $\mathrm{T} 1$, and $\Delta 4$ between $\mathrm{T} 2$ and $\mathrm{T} 1$.
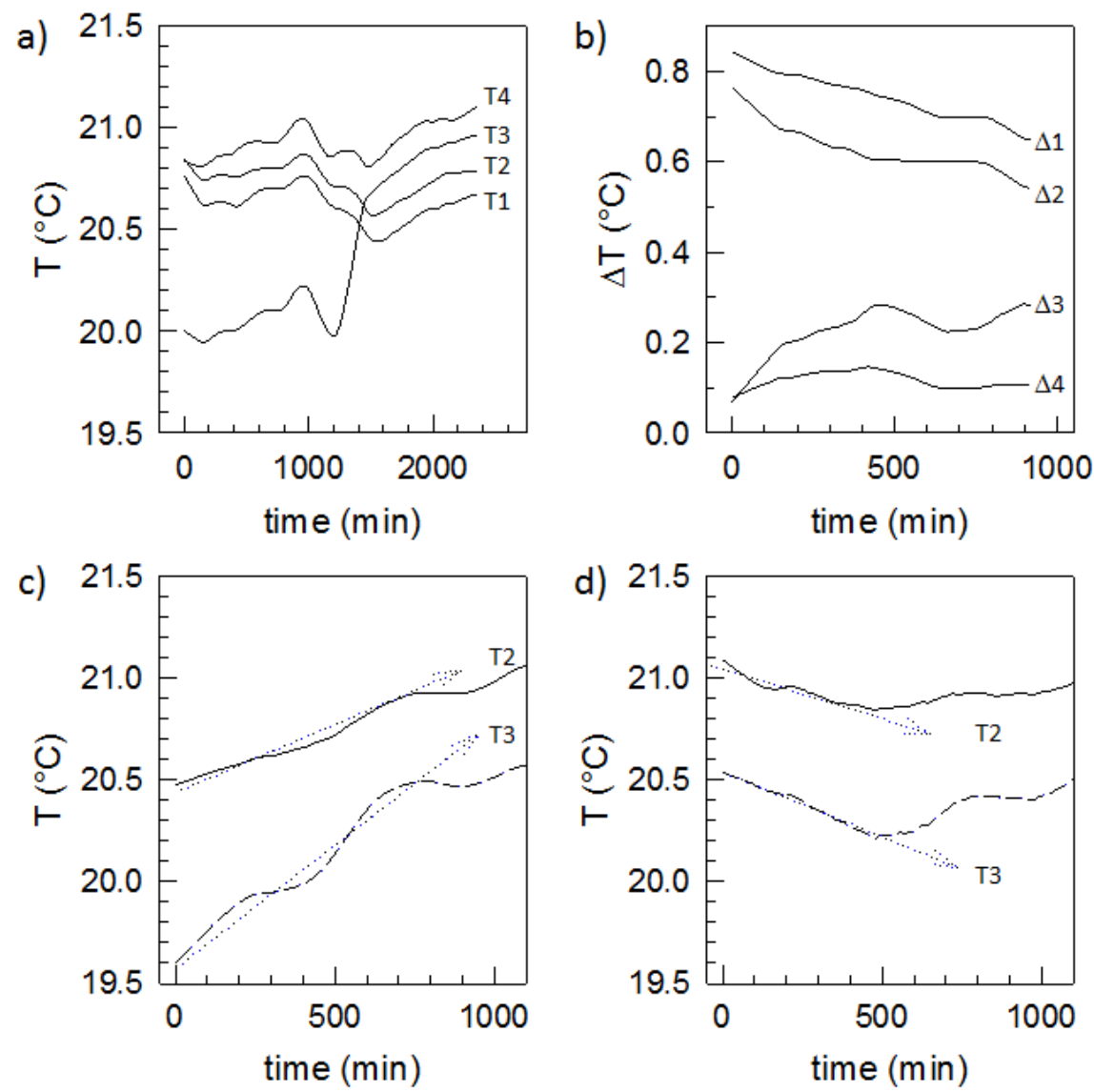

Figure 10. Evaluation of temperature changes during isochoric swelling for PAA (graph a), b), c), two repeats) and PNIPAM-PSS (graph d)) gels; a) - temperature profiles after establishing the contact between gel and water measured in the gel (T1), in the water pool (T2), in the water in the reference beaker (T3), in the air (T4), (PAA gel); b) - temporal changes of temperature differences: $\Delta 1=\mathrm{T} 2$ - T3, $\Delta 2=\mathrm{T} 1-\mathrm{T} 3, \Delta 3=\mathrm{T} 4-\mathrm{T} 1, \Delta 4=\mathrm{T} 2-\mathrm{T} 1$ (PAA gel); $\mathbf{c}$ - temperature profiles in the water pool (T2) and the water in the reference beaker (T3) (PAA gel); d) - temperature profiles in the water pool (T2) and the water in the reference beaker (T3) (PNIPAM-PSS gel)

The comparison of all temperature profiles, $\mathrm{T} 1-\mathrm{T} 4$, and the consideration of the temperature differences, $\Delta 1-\Delta 4$ shown in Figure $10 \mathrm{a}, 10 \mathrm{~b}$ and $10 \mathrm{c}$, lead to the same result regarding the heat effect during isochoric swelling of PAA gels. The data suggest that the process is endothermic because after establishing the contact with water heat is removed from the water pool indicated by decreasing $\Delta 1, \Delta 2$ and increasing $\Delta 3, \Delta 4$ values. Interestingly, this finding is in accordance with recently published data of swelling enthalpies of PAA gels under isobaric swelling conditions [36 ${ }^{29}$. In contrast to the PAA gel, the data for the PNIPAM-PSS gel show a much weaker response suggesting a slight exothermic heat effect. 
These results should not be overstated, since the observed changes are, under the given experimental conditions, very small.

\section{Summary and Conclusions}

We are discussing a new method to follow (almost) isochoric swelling of gels by measuring the apparent weight increase after establishing the contact between the confined gel sample and the swelling agent. The gel is located inside a confinement cell with porous walls which is completely immersed in an arbitrarily large pool of the swelling agent. The whole setup is placed on a scale with the confinement cell being tightly connected to an external reference point in a way that the force is redirected almost completely towards the scale. This arrangement permits easily to modify the conditions inside the reservoir of the swelling agent during the swelling process. The progress of swelling is followed by monitoring the apparent mass increase. Despite that the present setup is technically not optimized, the experimental results are in agreement with thermodynamic expectations and clearly prove the applicability of the apparent mass method to study the swelling pressure.

Examples are given for PAA (porous and solid gel samples) and PNIPAM hydrogels. The influences of modifications of the solvent quality such as the addition of ethanol or alterations of the $\mathrm{pH}$ and changes of the temperature in the water pool have been investigated. All these actions led to the expected changes in the swelling behavior of the gels, that is, decreasing the solvency caused a decrease in the apparent mass (scale readout) and vice versa. The method is also suited to detect the LCST of PNIPAM gels but surprisingly, only during the heating cycle. Interestingly, the changes of the apparent mass caused by the LCST of PNIPAM during cooling are overruled by the thermal contraction of the PTFE stamp. However, during heating the opposite behavior is observed meaning that the effect of the LCST is already at temperatures above $25.4^{\circ} \mathrm{C}$ much stronger than the thermal expansion of the PTFE stamp.

The method is principally also suited to study the heat effect associated with gel swelling but particularly in this respect the method needs constructive improvements.

A goal of future studies should be devoted to constructive and instrumental improvements of AMM. At the moment we see the following directions. The optimization of the pore size of the glass filter tube in dependence on the gel properties is necessary, particularly with respect to effectively prevent the gel to enter the pores. Another important issue is the search for an optimized combination of materials with respect to minimum thermal expansion. The implementation of a proper stirring device in the swelling agent pool in order to realize as much as possible isotropic conditions is especially important for studies with respect to the influence of the solvency of the swelling agent for the gel.

In summary, AMM is a new method for the experimentally easy study of gel swelling, particularly the investigation of the influence of the conditions in the reservoir of the swelling agent (temperature and chemical composition). Amongst others, an interesting application field of AAM might be studying the dissolution of drugs, mimicking in the water pool the condition in the gastrointestinal tract. The delivery of active pharmaceutics via oral administration of drugs requires swelling of the matrix followed by diffusion of the active component $[37,38]$. Due to its simplicity and particularly the easy accessibility of the swelling agent for modifications, this method has the potential to contribute to the development of new devices utilizing the swelling pressure for mechanical actuators. 


\section{Acknowledgements}

We thank J. von Szada and M. Bott, mechanical workshop, and C. Janiszewski, glassblower, of the MPI for careful production of the various devices tested for confining the gel samples. P.H. acknowledges a fellowship and financial support within the DFG priority program SPP1420. The authors are thankful to Ms. R. Yu for assistance with the URT measurements.

\section{References}

1. Engelmann TW (1895) CROONIAN LECTURE - On the Nature of Muscular Contraction. Proc Royal Soc, London 57:411 - 433

2. Harrington MJ, Razghandi K, Ditsch F, Guiducci L, Rueggeberg M, Dunlop JWC, FratzI P, Neinhuis C, Burgert I (2011) Origami-like unfolding of hydro-actuated ice plant seed capsules. Nat Commun 2. doi:Artn 337

Doi $10.1038 /$ Ncomms1336

3. Riecke E (1894) Zur lehre der Quellung. Wiedener's Annalen 53:564-592

4. Katz JR (1917) Die Gesetze der Quellung. Kolloidchemische Beihefte 9 (1-6):1 - 182

5. Posnjak E (1912) Über den Quellungsdruck. Kolloidchemische Beihefte III (12):417 - 454

6. von Schroeder P (1903) Über Erstarrungs- und Quellungserscheinungen von Gelatine. Zeitschrift für Physikalische Chemie 45:75 - 117

7. Borchard W (1966) Quellungsdruckmessungen an Polystyrolgelen. Rheinisch-Westfalische Technische Hochschule Aachen,

8. Borchard W, Emberger A, Schwarz J (1978) New Method to Determine Swelling Pressure. Angew Makromol Chem 66 (Jan):43-49. doi:DOI 10.1002/apmc.1978.050660104

9. Holtus G, Borchard W (1989) Swelling Pressure Equilibrium of Physical Networks in the Field of an Analytical Ultracentrifuge. Colloid Polym Sci 267 (12):1133-1138. doi:Doi 10.1007/Bf01496936

10. Holtus G, Colfen H, Borchard W (1991) Swelling pressure equilibrium of swollen crosslinked systems in an external field. II. Progress in Colloid and Polymer Scienec 86:92 - 101

11. Pennings AJ, Prins W (1961) Versatile Osmometer for Polymer Gels and Solutions with Applications to Cellulosic Gels. J Polym Sci 49 (152):507-\&. doi:DOI 10.1002/pol.1961.1204915230

12. Han IS, Han MH, Kim J, Lew S, Lee YJ, Horkay F, Magda JJ (2002) Constant-volume hydrogel osmometer: A new device concept for miniature biosensors. Biomacromolecules 3 (6):1271-1275. doi:Doi 10.1021/Bm0255894

13. Herber S, Olthuis W, Bergveld P (2003) A swelling hydrogel-based P-CO2 sensor. Sensor Actuat BChem 91 (1-3):378-382. doi:Doi 10.1016/S0925-4005(03)00121-7

14. Lin G, Chang S, Kuo CH, Magda J, Solzbacher F (2009) Free swelling and confined smart hydrogels for applications in chemomechanical sensors for physiological monitoring. Sensor Actuat B-Chem 136 (1):186-195. doi:DOI 10.1016/j.snb.2008.11.001

15. Siegel RA, Gu YD, Lei M, Baldi A, Nuxoll EE, Ziaie B (2010) Hard and soft micro- and nanofabrication: An integrated approach to hydrogel-based biosensing and drug delivery. J Control Release 141 (3):303-313. doi:DOI 10.1016/j.jconrel.2009.12.012

16. Wack $\mathrm{H}$, Ulbricht $M(2007)$ Method and model for the analysis of gel-blocking effects during the swelling of polymeric hydrogels. Ind Eng Chem Res 46 (1):359-364. doi:Doi 10.1021/le061077k 17. Wack $\mathrm{H}$, Ulbricht $M$ Gel Blocking Effects during the Swelling of Polymeric Hydrogels. In: First International Conference on Self Healing Materials, Noordwijk aan Zee, 18-20 April 20072007. 
18. Eisenberg SR, Grodzinsky AJ (1987) The Kinetics of Chemically Induced Nonequilibrium Swelling of Articular Cartilage and Corneal Stroma. Journal of Biomechanical Engineering 109 (1):79-89. doi:10.1115/1.3138647

19. Pons JL (2005) Emerging Actuator Technologies: A Micromechatronic Approach. John Wiley \& Sons, Ltd, New York

20. Rehage G (1960) Zur Thermodynamik der Quellung. Rheinisch-Westfälischen Technischen Universität Aachen,

21. van de Kraats EJ, Potters JJM, Winkeler MA, Prins W (1969) Polymer Network Characterization by Means of Swelling Pressure and Unilateral Compression Data. Recl Trav Chim Pay-B 88 (4):449-\&

22. Qin YM (2008) The gel swelling properties of alginate fibers and their applications in wound management. Polym Advan Technol 19 (1):6-14. doi:Doi 10.1002/Pat.960

23. Thompson EV (1989) Thermal Properties. In: Mark HF, I. KJ (eds) Encyclopedia of Polymer Science and Engineering, vol 16. J. Wiley \& Sons., New York, pp $711-747$

24. Bittrich E, Burkert S, Müller M, Eichhorn K-J, Stamm M, Uhlmann P (2012) Temperature-Sensitive Swelling of Poly(N-isopropylacrylamide) Brushes with Low Molecular Weight and Grafting Density. Langmuir 28 (7):3439-3448. doi:10.1021/la204230a

25. Hirose $\mathrm{H}$, Shibayama $\mathrm{M}(1998)$ Kinetics of volume phase transition in poly( $\mathrm{N}$-isopropylacrylamideco-acrylic acid) gels. Macromolecules 31 (16):5336-5342. doi:Doi 10.1021/Ma980405s

26. Lee WF, Hsu CH (1998) Thermoreversible hydrogel. V. Synthesis and swelling behavior of the Nisopropylacrylamide co trimethyl methacryloyloxyethyl ammonium iodide copolymeric hydrogels. J Appl Polym Sci 69 (9):1793-1803. doi:Doi 10.1002/(Sici)1097-4628(19980829)69:9<1793::AidApp14>3.0.Co;2-N

27. Liu HL, Liu MZ, Ma LW, Chen J (2009) Thermo- and pH-sensitive comb-type grafted poly(N,Ndiethylacrylamide-co-acrylic acid) hydrogels with rapid response behaviors. Eur Polym J 45 (7):20602067. doi:DOI 10.1016/j.eurpolymj.2009.03.019

28. Naini CA, Thomas M, Franzka S, Frost S, Ulbricht M, Hartmann N (2013) Hofmeister Effect of Sodium Halides on the Switching Energetics of Thermoresponsive Polymer Brushes. Macromolecular Rapid Communications 34 (5):417-422. doi:10.1002/marc.201200681

29. Nayak S, Debord SB, Lyon LA (2003) Investigations into the deswelling dynamics and thermodynamics of thermoresponsive microgel composite films. Langmuir 19 (18):7374-7379. doi:Doi 10.1021/La034390p

30. Wang X, Qiu X, Wu C (1998) Comparison of the Coil-to-Globule and the Globule-to-Coil Transitions of a Single Poly(N-isopropylacrylamide) Homopolymer Chain in Water. Macromolecules 31 (9):2972-2976. doi:10.1021/ma971873p

31. Lehmann S, Seiffert S, Richtering W (2012) Spatially Resolved Tracer Diffusion in Complex Responsive Hydrogels. J Am Chem Soc 134 (38):15963-15969. doi:Doi 10.1021/Ja306808j

32. Tauer K, Gau D, Schulze S, Hernandez H (2008) Transient-thermal and isothermal studies of thermo-sensitive polymer solution with ultrasound resonator technology. Polymer 49 (25):54525457. doi:DOI 10.1016/j.polymer.2008.09.066

33. Tauer K, Gau D, Schulze S, Volkel A, Dimova R (2009) Thermal property changes of poly(Nisopropylacrylamide) microgel particles and block copolymers. Colloid Polym Sci 287 (3):299-312. doi:DOI 10.1007/s00396-008-1984-x

34. Buckin V, Smyth C (1999) High-resolution ultrasonic resonator measurements for analysis of liquids. Seminars in Food Analysis 4 (2):113-130

35. Van Durme K, Delellio L, Kudryashov E, Buckin V, Van Mele B (2005) Exploration of highresolution ultrasonic spectroscopy as an analytical tool to study demixing and remixing in poly $(\mathrm{N}$ isopropyl acrylamide)/water solutions. J Polym Sci Pol Phys 43 (11):1283-1295. doi:Doi 10.1016/Polb.20423

36. Safronov AP, Kamalov IA, Shklyar TF, Dinislamova OA, Blyakhman FA (2012) Activity of counterions in hydrogels based on poly(acrylic acid) and poly(methacrylic acid): Potentiometric measurements. Polym Sci Ser a+ 54 (11):909-919. doi:Doi 10.1134/S0965545×12090088

37. Li CL, Martini LG, Ford JL, Roberts M (2005) The use of hypromellose in oral drug delivery. J Pharm Pharmacol 57 (5):533-546. doi:Doi 10.1211/00223570055957 
38. Rosilio V, Costa MD, Baszkin A (1998) Wettability of drug loaded polymer matrices. J Disper Sci Technol 19 (6-7):821-841. doi:Doi 10.1080/01932699808913217

\section{Supporting Information}

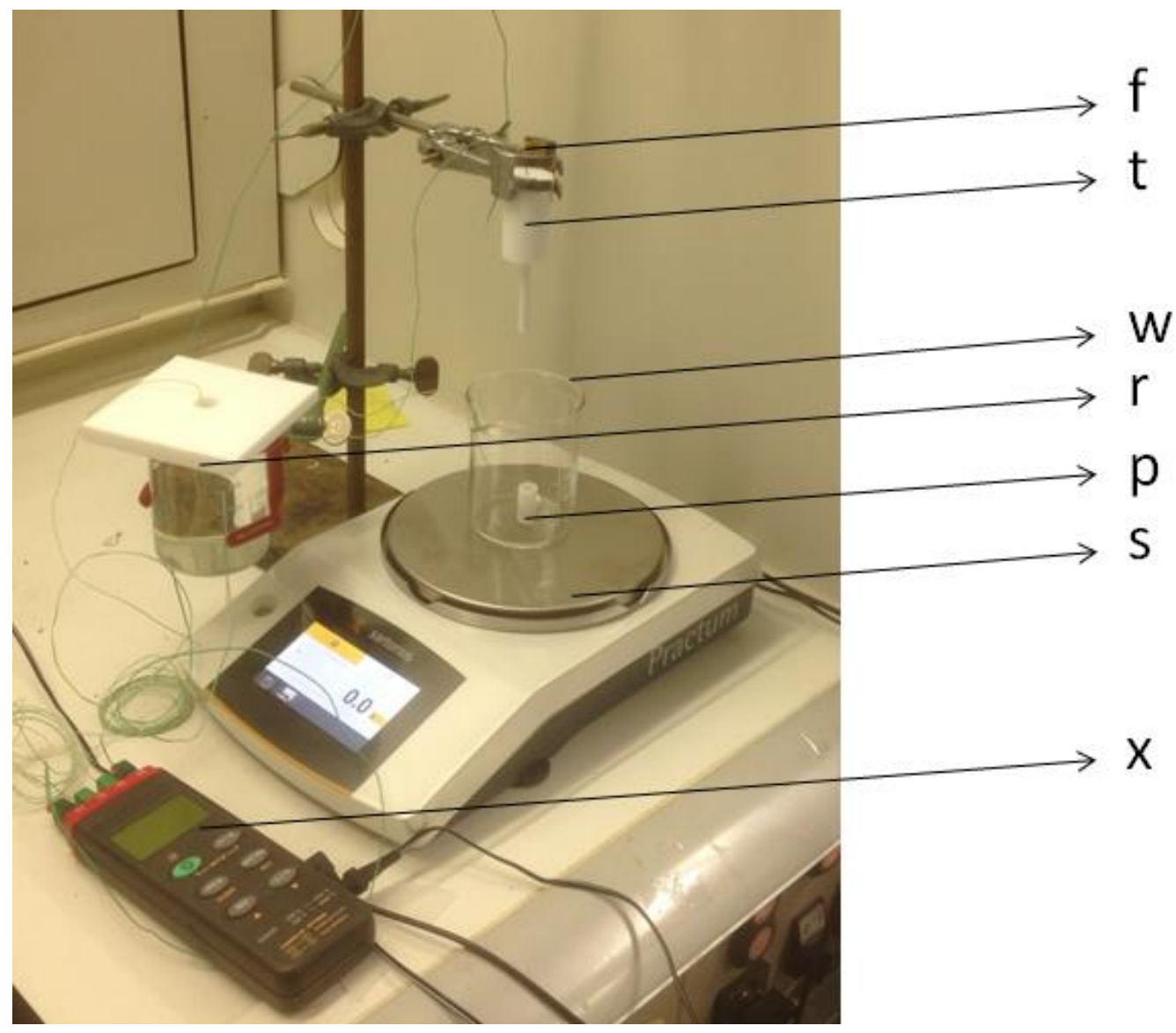

Figure S-1. Photograph showing the AMM setup; $s$ - scale connected with computer to automatically monitor data, $p$-porous glass filter tube (pore size G1, pore size $100-160 \mu \mathrm{m}$ ), t - PTFE stamp fitting to the porous glass filter tube, $f$ - clamp bolted to a fixed support stand, $w$ - beaker for the swelling agent, $x$ - digital thermometer, the green cables are the temperature sensors 
a)

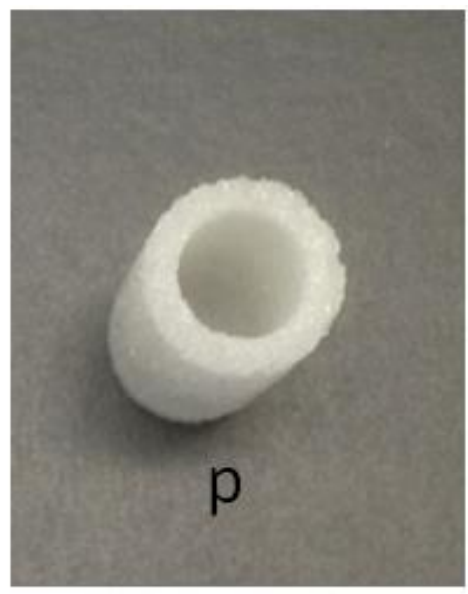

b)
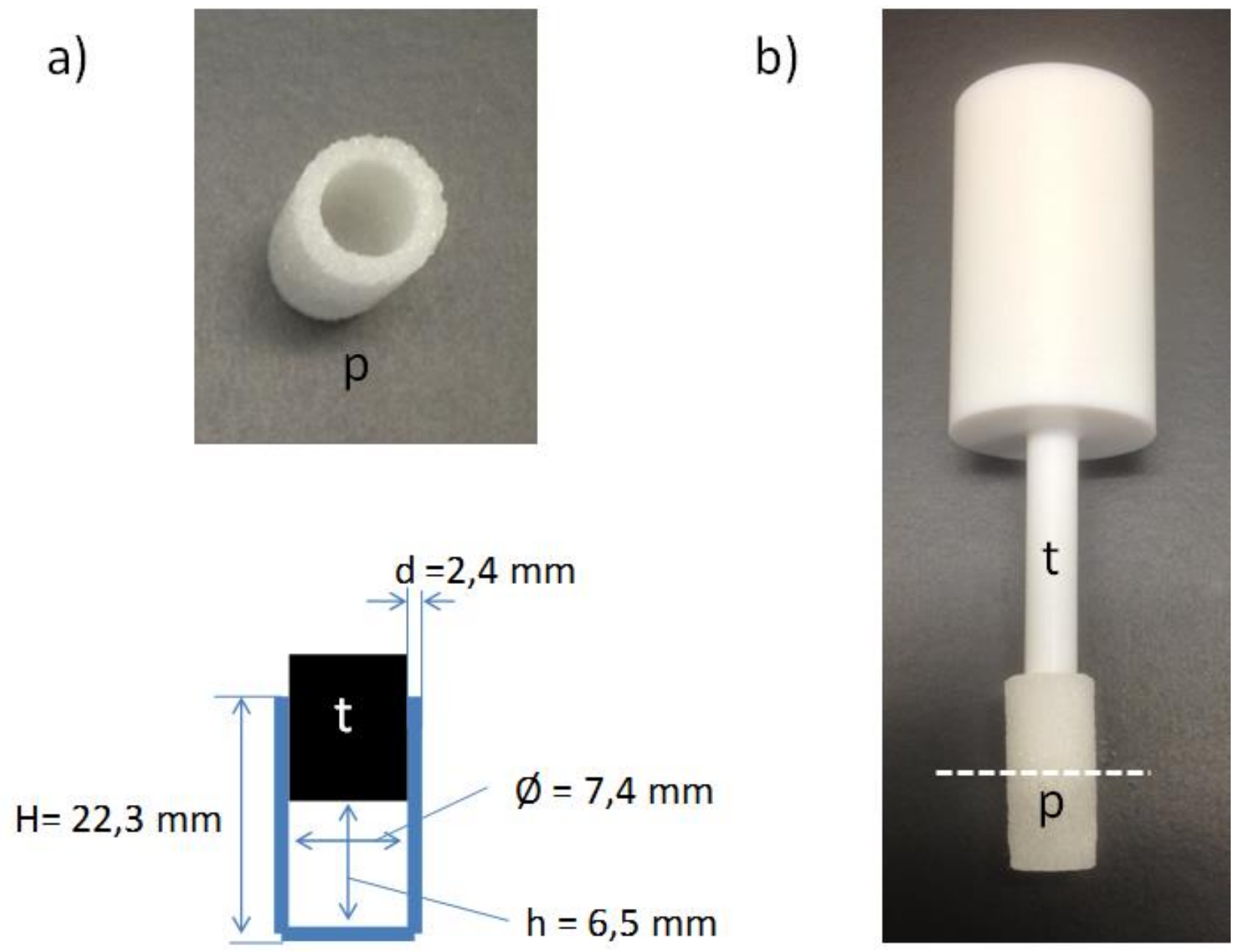

Figure S-2. Photographs showing a) the confining cell (upper part) with the dimensions (lower part) corresponding to case 4 of Figure 2 and b) the PTFE stamp in the confining cell, the dotted line marks the position of the bottom of the PTFE stamp in the confining cell; $p$-porous glass filter tube (pore size $\mathrm{G} 1$, pore size $100-160 \mu \mathrm{m}$ ), $\mathrm{t}$ - PTFE stamp fitting to the porous glass filter tube (the upper part of the PTFE stamp is thicker in order to facilitate mounting of the clamp) 